\title{
Evaluation of energy potential of fresh and stored bone marrow cells using a fluorescent potential-sensitive probe
}

\author{
Tatyana V.Parkhomenko, Oleg V.Galibin, Elena V.Verbitskaya, Vladimir V. Tomson \\ R.M. Gorbacheva Research Institute of Pediatric Oncology, Hematology and Transplantion, Research Center, First St.Petersburg \\ State I.P.Pavlov Medical University, Russian Ministry of Health Care, St.Petersburg, Russia \\ Parkhomenko T.V., Senior Research Associate, Laboratory of Pathomorphology, Research Center, The First St. Petersburg State \\ I.P. Pavlov Medical University, Russian Ministry of Health Care, L. Tolstoy St 6-8, 197022, St.Petersburg, Russia
}

Phone/Fax:+7(812) 499-71-54, e-mail: parhomenkotv@spb-gmu.ru.

\section{Summary}

Bone marrow is a primary source of hematopoietic stem cells in clinical transplantation. Quality of bone marrow grafts is a key factor of their successful in vivo expansion. The aim of our work was to test a semi-quantitative technique for assessment of bone marrow cell viability under strict storage conditions, by means of a fluorescent membrane potential-sensitive 2-Di-1-ASP probe.

We have studied 20 samples of normal bone marrow cells (BMC). The cells were placed in a standard storage solution with sodium citrate, citric acid; phosphate salts, dextrose and adenine. Cell counts and viability tests were performed up to 72 hours of incubation. The samples were labeled with 2-Di-1-ASP probe at specified terms. Fluorescence intensity was measured for single nucleated cells, followed by calculating mean fluorescence values and myelokaryocyte numbers. Mitotic indexes were determined both in Giemsa-stained and fluorescent probe-stained cells. Cluster analysis and non-parametric tests were used for statistical evaluation.

\section{Results}

Initial cell survival of $80-92 \%$ was shown at $3 . .5$ hours of storage, then decreased to $70-75 \%$ by the end of incubation. Meanwhile, cell incubation for 3 hours was accompanied by increased fluorescence, in terms of $\tilde{\mathrm{F}}$ values, mainly, due to higher proportion of "bright" cell population (>100 arb.units, $\mathrm{N}_{\mathrm{F}>100^{\circ}} \%$ ). D (ratio of $\mathrm{N}_{\mathrm{F}>100}$ at $3 \mathrm{~h}$ storage to $\mathrm{N}_{\mathrm{F}>100}$ initial) proved to be the most informative parameter, thus enabling us to predict sample-specific differences for the $\tilde{F}$ values at later terms. All BMC samples exhibited increased $\tilde{F}$, on the account of brighter cell population $\left(\mathrm{N}_{\mathrm{F}>100}\right)$, over 3 hours of incubation. This increase correlated with increase in myelokaryocyte counts. An additional cluster analysis allowed us to classify the BMC samples into 3 sub-groups, by their significant inter-group differences for D values and cell number changes. In particular, a number of mitotic cells were detected in BMC populations at 5 to 24 hours of incubation, showing bright stainability with 2-Di-1ASP probe. We revealed $0.60 \pm 0.10 \%$ of metaphase cells at initial time point. After 5-h storage, the frequency of mitotic cells increased to $1.4 \pm 0.1 \%$; and, after 6 -h colchicine treatment, the mitotic index increased to: $1.8 \pm 0.1 \%$, thus showing good preservation of dividing cell fraction.

In summary, our results have shown sustained, and even increased energy activity using a potential-sensitive probe, and good survival of mitotic cell fraction under strict incubation conditions. Appropriate mechanistic studies of the bone marrow cell preservation and energy balance under the given storage conditions should be performed in future.

\section{Keywords}

bone marrow cells, storage medium, cell survival, energy potential, mitotic activity, potential-sensitive probe. 


\section{Introduction}

Bone marrow transplantation (BMT) is widely used for treatment of different malignant and non-malignant disorders. Quality of hematopoietic cells the graft is a key factor of their successful in vivo expansion.

A classic method to determine colony-forming ability BMC is based on the cultures in semi-solid nutrient media with addition of growth factor cocktails $[3,11,17]$, however, requiring up to 3 weeks for evaluation. CD34+ cell count, a clinically recognized stem cell marker, is ascribed to a heterogenous population of committed and differentiating stem cell progenitors [16]. A more practical, however, less specific test is based on evaluation of aldehyde dehydrogenase (ALDH) activity [5] which is detected in viable hematopoietic stem cells and progenitors. Fluorescence intensity of reaction product is the measureable parameter, thus enabling ALDH-positive cell counts. Therefore, this method makes it possible to estimate in suspension proportion of intact stem cells and their progenies.

Meanwhile, the entire bone marrow cell (BMC) population is highly heterogeneous and contains a large number of mature blood cells and progenitors at different maturation stages. Therefore, energy state and metabolic activity of bone marrow cells are an important parameter of graft quality, especially, upon strict storage conditions. According to a current concept, the functional state of living cells is closely linked to their integrated energy-coupled characteristics (number of active mitochondria in the cytoplasm, transmembrane potentials of plasma and mitochondrial membranes). Changes in these parameters can be monitored in different cell populations using electric potential-sensitive fluorescent probes $[13,18]$. Transmembrane electric potential is a universal product of the systems of energy coupling. Application of methods using potential sensitive fluorescent probes allows to investigate the response of cells after exposure to various physical and chemical factors $[1,4,10,14]$, and to assess mitochondrial functions and redox potential of hematopoietic cells [8]. Earlier, we have revealed that intensity of fluorescent signal from cationic probe, iodide 2 [p-(dimethylamino)styryl]-1-methylpyridinium (2-Di-1-ASP) is sensitive to changes of energy potential in living cells, including BMC [12]. Moreover, this energy-dependent fluorescent probe is intended for evaluation of viable cells with intact outer membranes. Hence, appropriate fluorescence values reflect energetic state and general viability of the cell population under study.

Hence, the aim of our work was to test a method of rapid semi-quantitative assessment of bone marrow cell viability by means of a potential-sensitive vital 2-Di-1-ASP probe. A relationship was revealed between fluorescence intensity of the probe, cell viability and residual mitotic ability of marrow cell population during long-term storage.

\section{Materials and methods}

We have studied bone marrow cell samples (BMC) of healthy donors harvested for allogeneic transplantations at the R.M.Gorbacheva Memorial Research Institute of Children Oncology, Hematology and Transplantology. Harvesting of the bone marrow cell (BMC) suspensions was generally performed according to standard procedure [8]. The native cells were placed in a standard stabilizing solution («Terumo Corporation, Tokyo, Japan» ) containing $100 \mathrm{ml}$ of distilled water: of $2.63 \mathrm{~g}$ of sodium citrate; $0,327 \mathrm{~g}$ of citric acid; 0,251 $\mathrm{g}$ of dihydrophosphate sodium; $2.9 \mathrm{~g}$ dextrose anhydrous; $0,0275 \mathrm{~g}$ of adenine). The myelokaryocyte numbers were determined manually with a haemocytometer. The cell counts after incubation were expressed as percentages of initial cell numbers. Cell viability was determined by Trypan Blue exclusion test.

To determine mitotic indexes, the cell suspension was stored at room temperature (control). In parallel samples, the specimens were treated with colchicine (Acros Organics, Belgium) at a final concentration of $4.3 \mu \mathrm{g} / \mathrm{ml}$ added after 1 hour of storage, and incubated at $37^{\circ} \mathrm{C}$ for 5-24 hours. Suspension aliquots were taken at 5, 6, and 24 hours of storage, the cells were fixed according to May-Grünwald, and stained with Giemsa dye. Light microscopy was carried out with Leica DM 750 microscope (Germany), at a 1000x magnification. The pictures were obtained with ICC50 camera (Leica, Germany).

To evaluate energy potential of the cell samples, we used a fluorescent potential-sensitive cationic vital probe (iodide 2[p-(dimethylamino)styryl]-1-methylpyridine, 2-Di-1-ASP, Molecular Probes, Inc., Eugene, OR., USA). The cell aliquots of $0.9 \mathrm{~mL}$, were stored in standard stabilizing solution at a concentration of $\sim 2-3 \times 10^{7}$ cells $/ \mathrm{ml}$ in Eppendorf tubes of 1.5 $\mathrm{ml}$ at room temperature $\left(20 .-.22^{\circ} \mathrm{C}\right)$. At defined time points (1 to 72 hours), the cell suspensions were mixed, and $30-\mu l$ aliquots were taken and brought to the $0.6-\mathrm{mL}$ Eppendorf tubes, supplied with 2-Di-1-ASP at a final concentration of $40 \mu \mathrm{m}$, and incubated at $37^{\circ} \mathrm{C}$ for $60 \mathrm{~min}$. The cell suspensions $(3 \mu \mathrm{l})$ were then evaluated in a Lumam-I2 luminescence microscope (Russia). at a 900x magnification. A FMEL-1 photometric device with interference filter was used, at maximal transmittance of $585 \mathrm{~nm}$. Excitation and emission (registration) wavelengths were, respectively, 470 and $560 \mathrm{~nm}$. Fluorescence intensity signals were recorded from single cells. Seventy to hundred cells per sample were tested manually, and the mean cell fluorescence intensity ( $\tilde{\mathrm{F}}$, arbitrary units) was calculated for each specimen. The studied cells were graded into four classes by their mean $\tilde{\mathrm{F}}$ values (resp., 10-30; 30-70; 70-100, and $>100$ arbitrary units). Photographic pictures of luminescent objects were performed with TCA-5.0 camera, using "Micro-Analysis View" software (LLC "LOMO-Microsystems", Russia). Statistical analysis of $\tilde{F}$ and cell number changes was performed by ANOVA Repeated Measures analysis for variance-dependent samples [2]. The 
donor samples were classified by cluster analysis (Euclidean metric), the nearest mean strategy). The significance of differences was evaluated by Wilcoxon-Mann-Whitney criterion. The differences between the groups were considered significant at $\mathrm{P} \leq 0.05$.

\section{Results}

Bone marrow cell suspensions stored in a preserving medium showed some initial decrease in cell survival, i.e., 8 to $20 \%$ of the cells were Trypan Blue-positive. By the end of storage (72 hours) the mean numbers of Trypan Blue-positive cells increased to $25-30 \%$. Meanwhile, subsequent cell incubation for 3 hours was accompanied by increased fluorescence, in terms of $\tilde{\mathrm{F}}$ values, mainly, due to higher proportion of "bright" cell population ( $\geq 100$ arb.units, $\left.\mathrm{N}_{\mathrm{F}>100}, \%\right)$ $\mathrm{D}$ (ratio of $\mathrm{N}_{\mathrm{F}>100}$ at $3 \mathrm{~h}$ storage to $\mathrm{N}_{\mathrm{F}>100}$ initial) proved to be the most informative parameter and allows to predict sample-specific differences for $\tilde{\mathrm{F}}$ values at later terms. We assumed the $\mathrm{D}$ value to be the main parameter reflecting energetic potential of BMC. A cluster analysis was performed, thus allowing us to classify the BMC samples into 3 sub-groups, according to significant inter-group differences in $\mathrm{D}$ values $(\mathrm{P}<0.0001)$ as shown in Fig.1. Cell fluorescence values in groups 1, 2 and 3 showed, respectively, minimal, maximal and intermediate increase rates in $\tilde{\mathrm{F}}$ и $\mathrm{N}_{\mathrm{F}>100}$ after 3-h incubation. (Table 1).

Cell counts and $\tilde{\mathrm{F}}$ values for later terms (since 5 hours of incubation) were evaluated by means of ANOVA dispersion analysis for repeated measurements. Significant intergroup differences were revealed for both $\tilde{F}$ values $(\mathrm{P}=0.005)$ (Fig. 2$)$ and nucleated cell numbers $(\mathrm{P}<0.0001)$ (Fig. 3). Hence, a total group of BMC samples could be divided into 3 subgroups, according to sustained increment of potential-dependent fluorescence and cell number changes.

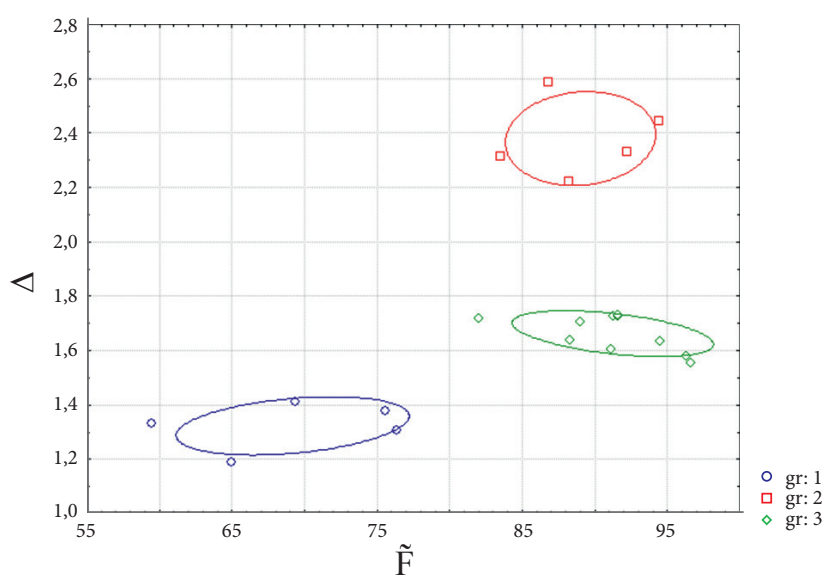

Fig. 1. Distribution by dependence $D$ (ratio of $N_{F>100}$ at 3h storage to $\mathrm{N}_{\mathrm{F}>100}$ initial) on initial fluorescence values $(\tilde{\mathrm{F}})$. Abscissa: Mean $\tilde{\mathrm{F}}$ values for individual donors; Ordinate: ratio of $\mathrm{N}_{\mathrm{F}>100}$ at $3 \mathrm{~h}$ to $\mathrm{N}_{\mathrm{F}>100}$ initial. Groups 1 , 2 , and 3 showed, respectively, minimal, maximal and intermediate increase rates in $\tilde{\mathrm{F}}$ and $\mathrm{N}_{\mathrm{F}>100}$ at $3 \mathrm{~h}$ as compared to initial fluorescence levels.

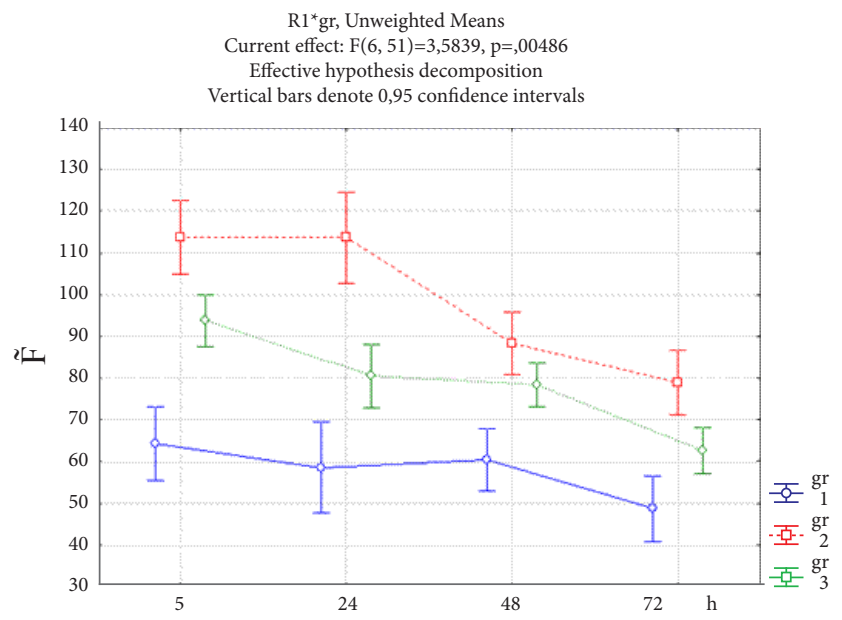

Fig. 2. Changes of mean fluorescence values in stored BMC samples. Abscissa, storage time (hours), ordinate, mean fluorescence values $(\tilde{\mathrm{F}})$ for each time point. Groups 1, 2 and 3 showed, respectively, minimal, maximal and intermediate shifts in $\tilde{\mathrm{F}}$ and $\mathrm{N}_{\mathrm{F}>100}$ following 3 hours of storage.

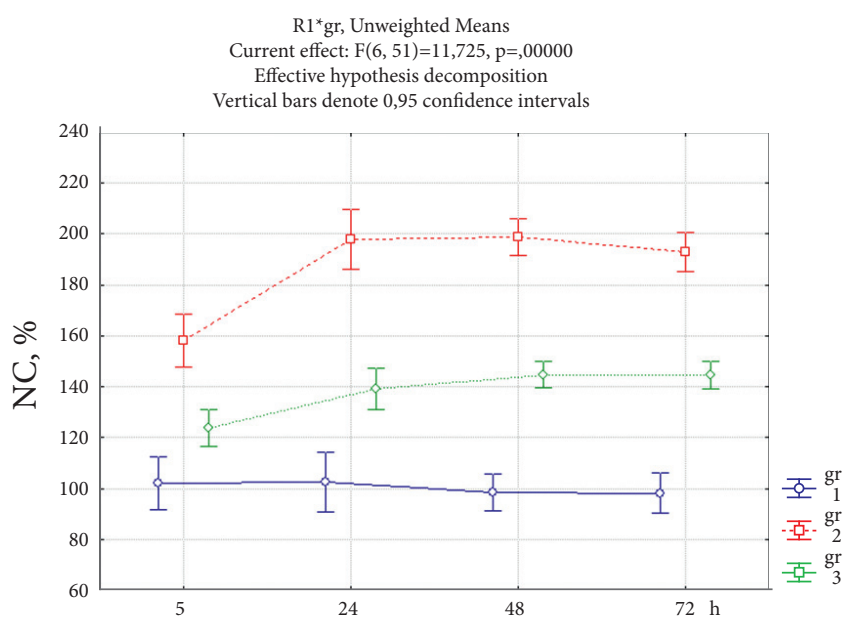

Figure 3. Changes in nucleated cell numbers (\%) during BMC storage in standard stabilizing solution. Abscissa, storage time (hours), ordinate, nucleated cell numbers (\%) for each time point. Groups 1, 2 and 3 showed, respectively, minimal, maximal and intermediate shifts in $\tilde{\mathrm{F}}$ and $\mathrm{N}_{\mathrm{F}>100}$ following 3 hours of storage. 
Table 1. Mean values for BMC counts (NC), mean fluorescence ( $\tilde{\mathbf{F}})$ and proportion of highly fluorescent subpopulation $\left(\mathrm{N}_{\mathrm{F}>100}\right)$ at initial terms and following 3 hour-incubation for the 3 groups of BM samples

\begin{tabular}{|l|l|l|l|l|}
\hline Group & Parameter & 0 hours & 3 hours & $\mathrm{P}$ \\
\hline 1 & $\tilde{\mathrm{F}}_{1}$ arb.uints & $69,99 \pm 2,63$ & $79,61 \pm 2,50$ & 0,043 \\
\hline 1 & $\mathrm{~N}_{\mathrm{F}>10^{\circ}} \%$ & $21,07 \pm 2,17$ & $27,7 \pm 2,67$ & $0,0431,37$ \\
\hline 1 & $\mathrm{NC} \%$ & 100,00 & $100,18 \pm 0,06$ & 0,067 \\
\hline 2 & $\tilde{\mathrm{F}}_{1}$ arb.units & $89,04 \pm 1,93$ & $147,74 \pm 8,71$ & 0,043 \\
\hline 2 & $\mathrm{~N}_{\mathrm{F}>100^{\prime}} \%$ & $32,44 \pm 1,83$ & $76,73 \pm 2,51$ & $0,0432,36$ \\
\hline 2 & $\mathrm{NC} \%$ & 100,00 & $118,60 \pm 2,29$ & 0,043 \\
\hline 3 & $\tilde{\mathrm{F}}_{1}$ arb.units & $91,22 \pm 1,40$ & $122,27 \pm 2,63$ & 0,005 \\
\hline 3 & $\mathrm{~N}_{\mathrm{F}>100^{\prime}} \%$ & $40,39 \pm 1,31$ & $66,97 \pm 1,74$ & $0,0051,66$ \\
\hline 3 & $\mathrm{NC} \%$ & 100,00 & $102,5 \pm 0,62$ & 0,0076 \\
\hline
\end{tabular}

Note: $\mathrm{M} \pm \mathrm{m}$ values are shown for each time point.

As seen from Table 1, the $\Delta$ (ratio of $\mathrm{N}_{\mathrm{F}>100}$ at $3 \mathrm{~h}$ to $\mathrm{N}_{\mathrm{F}>100}$ initial) values show a 1.3 - to 2.4 -fold increase, depending on the BM sample group, especially, for groups 2 and 3.

Hence, all the BMC samples exhibited increased $\tilde{F}$ over 3 hours of incubation, mostly, due to "bright" cell subpopulation $\left(\mathrm{N}_{\mathrm{F}>100}\right)$,. This increase correlated with elevation of cell counts in suspension.

Preservation of dividing cells under these storage conditions was confirmed by means of standard karyological methods. In particular, a number of mitotic cells were detected in BM suspensions over 5 to 24 hours of incubation, being

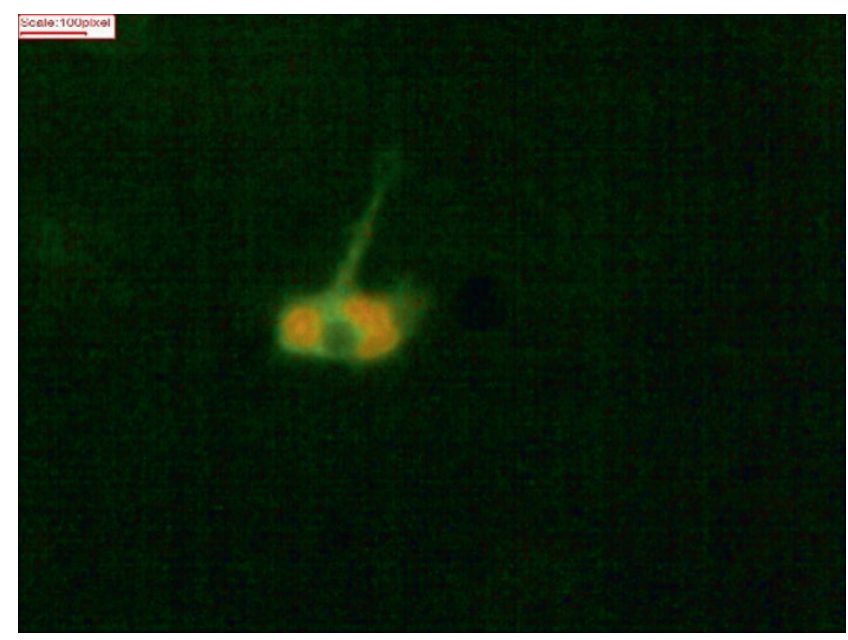

A

Fig.4. Mitotic figures in preparations of stored BMC (2-Di-1-ASP probe staining) (A) - 5-h incubation, 250 arb.units; (B)- 6-h incubation; 110 arb.units. stainable with the 2-Di-1-ASP probe (Fig. 4). Frequency of mitotic patterns in BMC aliquotes taken at different time points was studied in a special series of BM samples $(n=5)$ The mitotic figures were of typical appearance (Fig. 4). All the samples were analyzed in triplicate. In summary, we have found $0.60 \pm 0.10 \%$ of metaphase cells at initial time point. After 5-h storage, the frequency of mitotic cells increased to $1.4 \pm 0.1 \%$; and, after 6 - colchicine treatment, the mitotic index increased to: $1.8 \pm 0.1 \%$. By 24 hours the mitotic indices did not significantly differ from the 6-hour values.

Hence, a sufficient portion of pre-mitotic BM cells showed their ability to divide even after several hours of storage in rather simple medium devoid of growth factors.

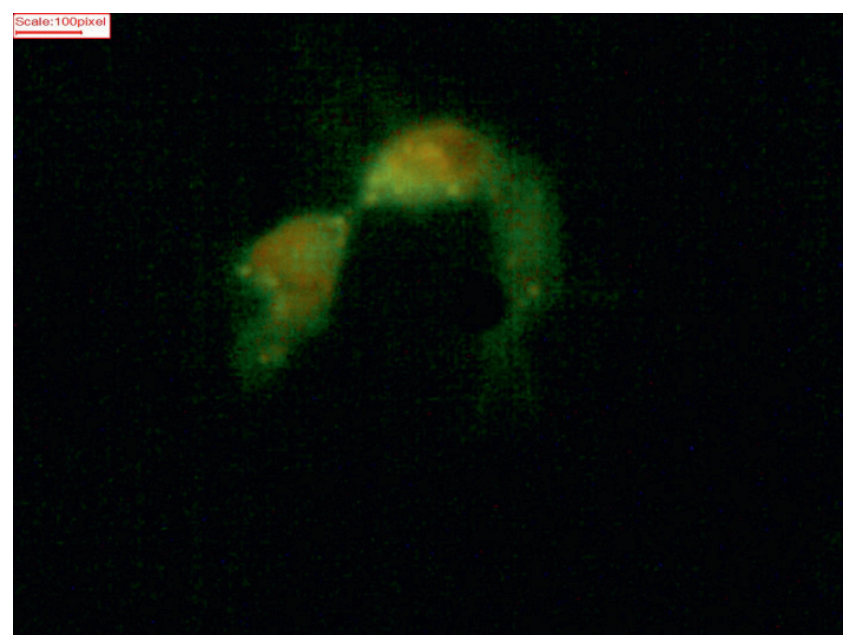

B 


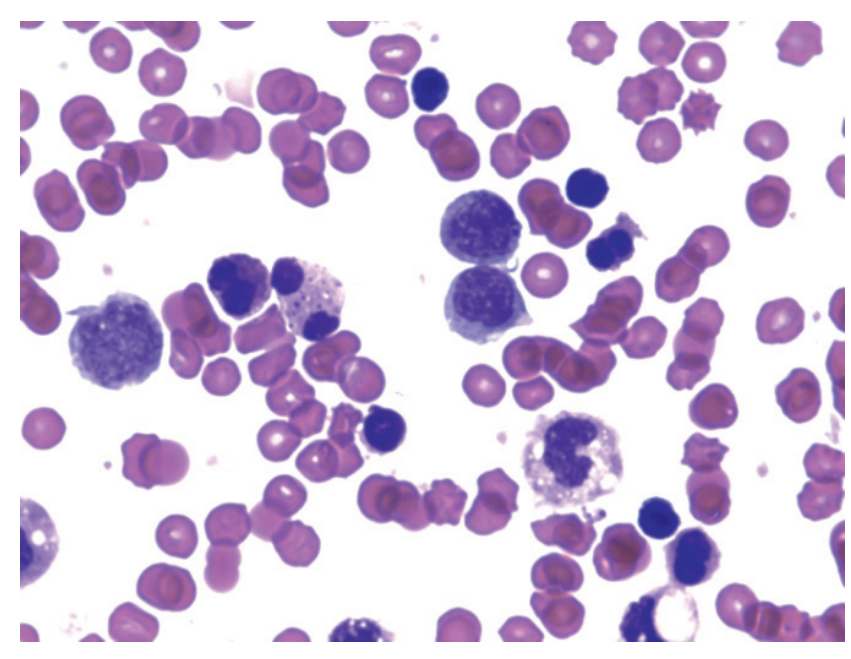

A

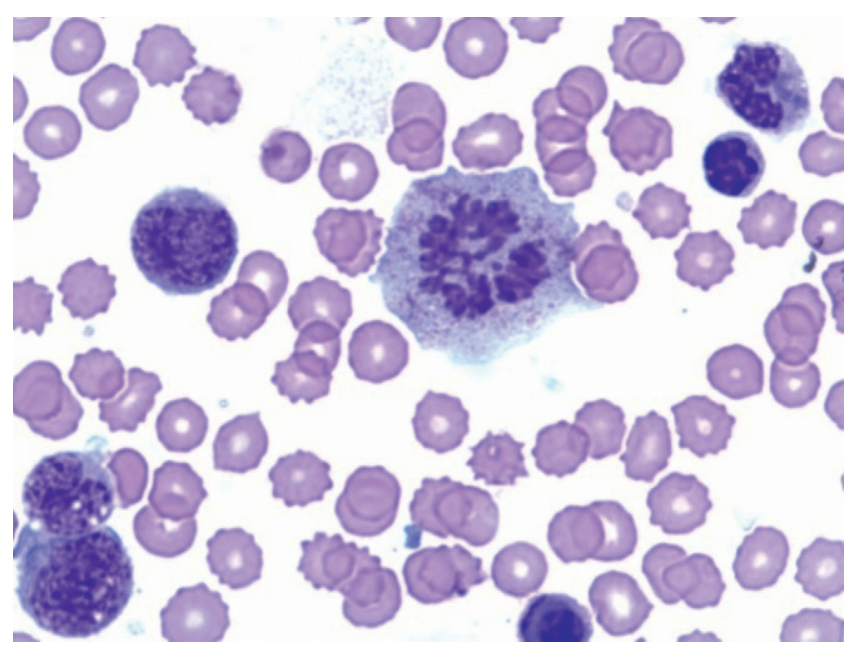

B

Fig 5. Mitotic figures in preparations of stored $B M C$, (A) $-6 \mathrm{~h}$ incubation (colchicine-free control); (B) - mitosis of granulosytic precursor (6-h with colchicine).

\section{Discussion}

Synthetic fluorescent probes showing affinity for mitochondrial membranes are increasingly studied over last decades [15]. Vital cationic probes are used to follow the changes of transmembrane potential which may be registered by microscopy and, potentially, by flow cytometry in different cell populations. Modern experimental protocols with microwell incubation under defined conditions and supplements have been proposed for assessment of bioenergetic changes in cell cultures [7]. In this respect, our general approach well fits current trends in searching bioenergetic parameters of stored cell samples.

Our data presume good preserving properties of a simple marrow conservant containing dextrose, adenine, dihydrophosphate sodium and citrate ions at optimal concentrations. Previous studies were performed with cells stored under physiological conditions. E.g., Lioznov et.al., [9] have studied stability of bone marrow and peripheral blood stem cells at different temperatures. Indeed, the hematopoietic stem cells remained relatively intact for several days at $+4^{\circ} \mathrm{C}$, without significant decrease of proliferative capacity. By contrary, incubation of peripheral stem cells at room temperature is followed by decreased numbers of GM-CFUs to $<20 \%$ of initial levels, whereas GM-CFU numbers in bone marrow transplants was retained for, at least, 72 hours. We have shown increased cell numbers in BMC samples after $5 . .24$ hours of incubation in the stabilizing solution, further remaining near-constant until 72 hours at room temperature. One may suggest that the BM cells retained their viability (as Trypan Blue-negative forms) and energetic potential after 72-h incubation, even under suboptimal physiological conditions. Our previous studies have shown that the stabilizing solution well preserves BMC as compared to storage in physiological saline, or Hanks' medium. [12]

More detailed data concerning possible associations between the energy potential determined with fluorescent probe, and other criteria of cell viability should be obtained in future studies, employing advanced experimental protocols.

\section{Conclusion}

We have proposed a method for evaluation of storage conditions for bone marrow cells using a supravital fluorescent potential-sensitive 2-Di-1-ASP probe, upon incubation at room temperature in a standard hemoconservant solution. This method may be applied, e.g., for comparative studies of different storage media and treatment regimens for bone marrow samples. Such biophysical approach allows quantitative evaluation of energetic activation, by increasing fluorescence in total cell population at early terms of storage. A correlation was revealed between higher fluorescence rates, increased proportion of "bright" (energetically active) subpopulation, and higher cell counts. Finally, our results have shown maintenance of mitotic cell fraction under the applied incubation conditions. Next step of our studies will include development of high-throughput flow cytometry technique for this fluorescence test. Appropriate mechanistic studies of the bone marrow cell preservation and energy balance should be performed in future.

\section{Acknowledgements}

The authors are much appreciated to Lyudmila A.Belyakova (Waldman Institute of Pharmacology) for skilful data analysis, Valentina M.Kravtsova, and Tatyana L Gindina (R.Gorbacheva Research Institute of Children Oncology, Hemaptology and Transplantation) for expert evaluation of bone marrow smears.

\section{Conflict of interests}

The authors have no conflicts of interests to declare 


\section{References}

1. Artuhov VG, Putinzetva OV, Bragina VA, Pashkov MV, Vasilenko DV. Fluorescent methods in the research induced by UV radiation changes of structural and functional state of human blood lymphocytes. Bull Exp Biol Med 2012;153(6):891-895.

2. Afifi AA, Azen SP. Statistical Analysis, Second Edition: A Computer Oriented Approach Academic Press: N.-Y.-London, $1979,366 \mathrm{p}$.

3. Dygai AM, Skurihin EG, Pershina OV, Andreeva TV, Hmelevskaya ES, Minakova MY. The role of hemopoietic precursors of various classes in the mechanisms of action of granulocyte colony-stimulating factor on hematopoiesis in cytostatic myelosuppression. Bull Exp Biol Med 2010; 149(4):400-404.

4. Ito S; Kusuhara $\mathrm{H}$; Yokochi $\mathrm{M}$, Toyoshima J, Inoue $\mathrm{K}$; Yuasa H, Sugiyama Y. Competitive inhibition of the luminal efflux by multidrug and toxin extrusions, but not basolateral uptake by organic cation transporter 2 , is the likely mechanism underlying the pharmacokinetic drug-drug interactions caused by cimetidine in the kidney. J Pharmacol Exp Ther 2012;340 (2):393-403.

5. Jones RJ, Barber JP, Vala MS, Collector MI, Kaufmann SH, Ludeman SM, Colvin OM, Hilton J. Assessment of aldehyde dehydrogenase in viable cells. Blood 1995; 85(10):2742-2746.

6. Kaur A, Jankowska K, Pilgrim C, Fraser ST, New EJ. Studies of Hematopoietic Cell Differentiation with a Ratiometric and Reversible Sensor of Mitochondrial Reactive Oxygen Species. Antioxid Redox Signal. 2016; 24(13): 667-679.

7. Kramer PA, Chacko BK, Ravi S, Johnson MS, Mitchell T, Darley-Usmar VM. Bioenergetics and the oxidative burst: protocols for the isolation and evaluation of human leukocytes and platelets. J Vis Exp 2014; (85). doi: 10.3791/51301.

8. Lannert $\mathrm{H}$, Able $\mathrm{T}$, Becker $\mathrm{S}$, Sommer $\mathrm{M}$, Braun $\mathrm{M}$, Stadtherr P, Ho A. Optimizing BM harvesting from normal adult donors. Bone Marrow Transplantation 2008; 42:443-447.
9. Lioznov M.V., Freiberger P., Kroger N., Zander A.R., Fehse B. Aldehyde dehydrogenase activity as a marker for the quality of hematopoietic stem cell transplants. Bone Marrow Transplant 2005, 35,(9):909-914.

10. Morozova GI, Parkhomenko TV, Klitsenko OA, Tomson VV. Stimulating effect of erythropoietin on thymocyte energetics established in vitro with a potential-sensitive fluorescent probe in the mitochondria. Biochem. Suppl. Series A: Membr Cell Biology 2007;1(4):325-330.

11. Nissen-Druey C, Tichelli A, Meyer-Monard S. Human hematopoietic colonies in health and disease. Acta Haematol 2005;113(1):5-96.

12. Parkhomenko TV, Galibin OV, Mikhailova NB, Babenko EV, Tomson VV. A method for determining the activity of the bone marrow cells. 2013. Russian patent RU №2488826, Bull. № 21. (In Russian)

13. Parkhomenko TV, Klytsenko OA, Tomson VV. Erythropoietin stimulates aerobic and anaerobic processes in rat cardiomyocytes. Focus Uni-Lübeck. Suppl. 2012, P. 37.

14. Parkhomenko TV, Morozova GI, Klytsenko OA, Tomson VV. Evaluation of restoring Erythropoietin (EPO) effect on rat T-lymphocytes after their treatment with some inhibitors in vitro. Ann Hematol 2003;82(6):S114.

15. Solaini G, Sgarbi G, Lenaz G, Baracca A. Evaluating mitochondrial membrane potential in cells. Biosci Rep 2007; 27(1-3):11-21.

16. Sutherland DR, Anderson L, Keeney M, Nayar R, ChinYee I The ISHAGE guidelines for $\mathrm{CD} 34^{+}$cell determination by flow cytometry. International Society of Hematotherapy and Graft Engineering. J. Hematother 1996; (5):213-226.

17. Ventura GJ, Hester JP, Buescher ES, Vadhan-Raj S, Durrett A, Reading CL Hematopoiesis in limiting dilution cultures: influence of cytokines on human hematopoietic progenitor cells. Exp Hematol 1990; 18(8):878-882.

18. Vida TA, Emr SD. A new vital stain visualizing vacuolar membrane dynamics and endocytosis in yeast. J Cell Biol 1995; 228(5): 779-792. 